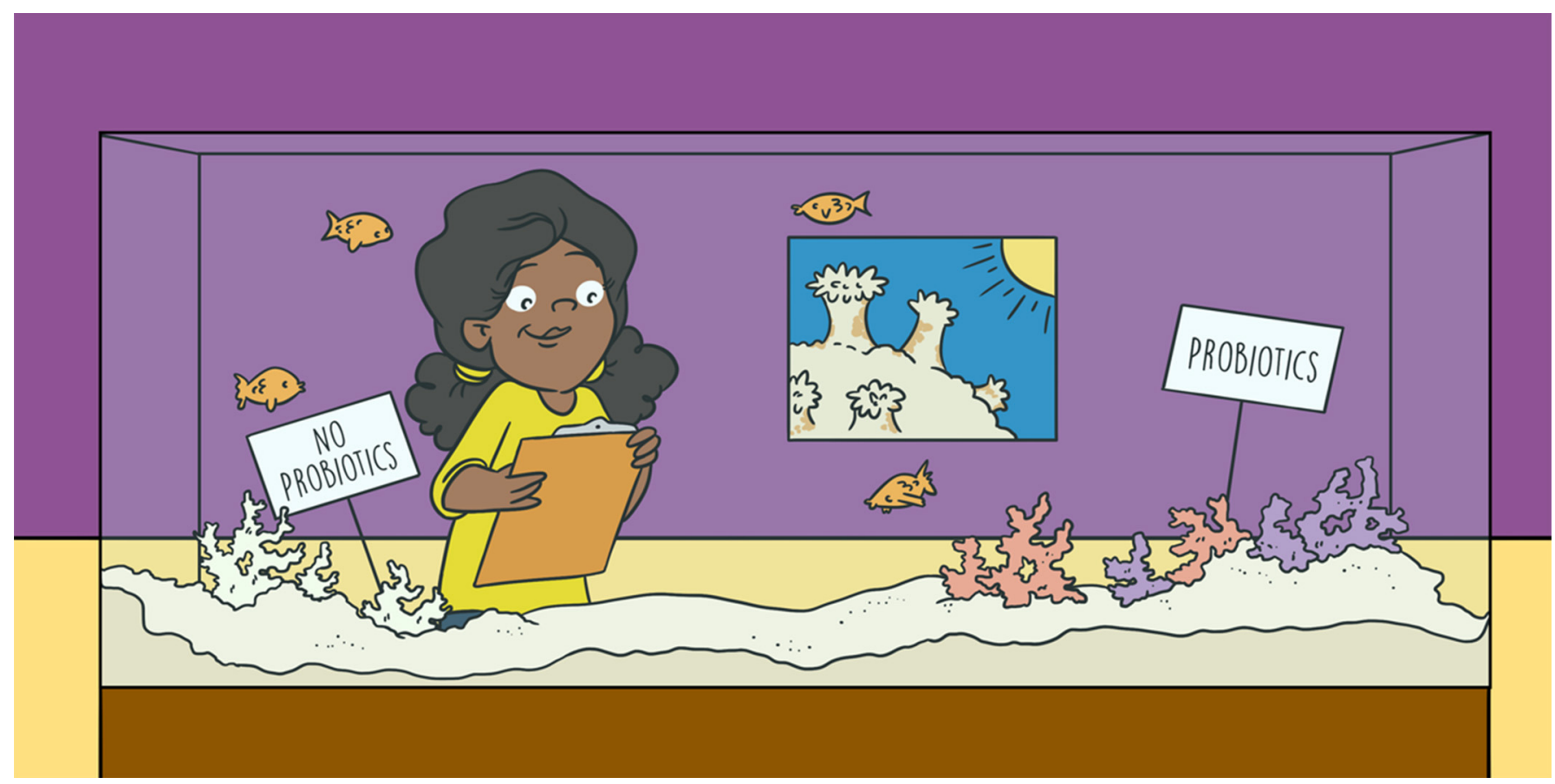

\title{
AN INCREDIBLE INVISIBLE WORLD: HOW MICROORGANISMS COULD TAKE CARE OF CORALS IN DIFFICULT TIMES
}

\section{Phillipe Rosado ${ }^{1}$, Natascha Varona ${ }^{2}$, Jonathan A. Eisen ${ }^{2}$ and Raquel S. Peixoto ${ }^{1,2,3^{*}}$}

${ }^{1}$ Molecular Microbial Ecology Laboratory, Paulo de Góes Institute of Microbiology, Federal University of Rio de Janeiro, Rio de Janeiro, Brazil

${ }^{2}$ Genome Center, University of California, Davis, Davis, CA, United States

3IMAM-AquaRio-Rio de Janeiro Aquarium Research Center, Rio de Janeiro, Brazil

YOUNG REVIEWERS:

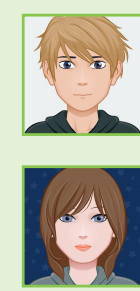
BRAYDEN

AGE: 11

CECILIA

AGE: 11

NAGA

AGE: 15

SAGE

AGE: 10
Have you ever dived into the ocean and seen several colored "rocks" in the water? Those "rocks" might actually be animals called corals! Corals form coral reefs and they are very important, because thousands of marine animals depend on them for survival. Did you know that corals and humans have something in common? Both have what are called mutualistic microorganisms (or as we like to call them, M\&Ms) living within them! Mutualistic microorganisms are tiny organisms that strengthen and help both humans and corals when they start to get sick. One of the main causes of coral disease and death is rising seawater temperature. The curious thing is that in some places, such as the Red Sea, the temperature of the oceans is higher than it is in other places, yet there are several corals living happily there. How is this possible? Are M\&Ms one of the factors helping corals survive in these high-temperature environments? 
SAVANA

AGE: 13

UMAIRAH

AGE: 15

\section{PHOTOSYNTHESIS}

A chemical process used by many organisms (e.g., plants, many microbes) to use the energy of light to make sugars from carbon dioxide.

\section{MUTUALISM}

The interaction between two or more species, in which each organism benefits from the interaction in some way.

\section{PROBIOTICS}

Living microorganisms that provide health benefits when in traduced to a host.

\section{AN ANCIENT ANIMAL NEEDS HELP}

Corals have been around for a long time, living in the oceans for millions of years, probably even before the dinosaurs existed. Currently, coral reefs cover only $1 \%$ of the ocean area, but one out of four marine animals rely on coral reefs to survive. It is in coral reefs that these sea animals find food, make their homes, protect themselves from predators, and breed their young [1]. What if corals vanished forever? Where would all other coral-dependent animals live? It would surely be a great disaster (Figure 1).

One of the big threats to coral is the rising temperature of the oceans. Although corals have been around for millions of years, they are fragile animals in some ways, particularly when it comes to changes in temperature. Here is what happens: there are organisms called zooxanthellae (pronounced zoo-uh-zan-thel-ee), which are very small and live inside most of the shallow-water corals. These zooxanthellae can carry out photosynthesis; in other words, they can turn sunlight into food. They are so efficient at producing food from sunlight that they can feed themselves and feed the coral as well. Therefore, the main source of food and energy for these corals to grow comes from the zooxanthellae that live inside them. In return, corals protect the zooxanthellae and provide some nutrients to help them grow. This very friendly relationship between coral and zooxanthellae is known as mutualism.

As ocean temperatures rise, largely due to global warming and the greenhouse effect, the friendly relationship between corals and zooxanthellae becomes less friendly. Zooxanthellae start to produce less food, as well as some toxic compounds, and corals start to kick them out of their homes. In this way, corals lose their main source of energy, and also lose the beautiful brownish/greenish colors they once had, turning white. This phenomenon is called coral bleaching [2]. Because zooxanthellae help to protect corals from the sun, when corals are bleached, they are unprotected from the harmful effects of direct sunlight. In extreme cases, some corals will try to protect themselves by increasing their own bluish, yellowish, or purple colors [3]. These bright colors act as a sunscreen and are the last resort some corals have to protect themselves from the sun.

If corals lose zooxanthellae for a long period of time, they will not have the necessary energy to survive and will eventually die. This is the main negative impact of rising ocean temperatures, and it is at this point that M\&Ms may be able to help corals, through their role as probiotics. 
Figure 1

(A) A healthy coral reef, with other living marine beings living in harmony. (B) An unhealthy, bleached coral reef, without other living marine beings.

\section{HOST}

An organism that houses another organism as a guest, with the guest typically receiving nourishment and shelter from the host.
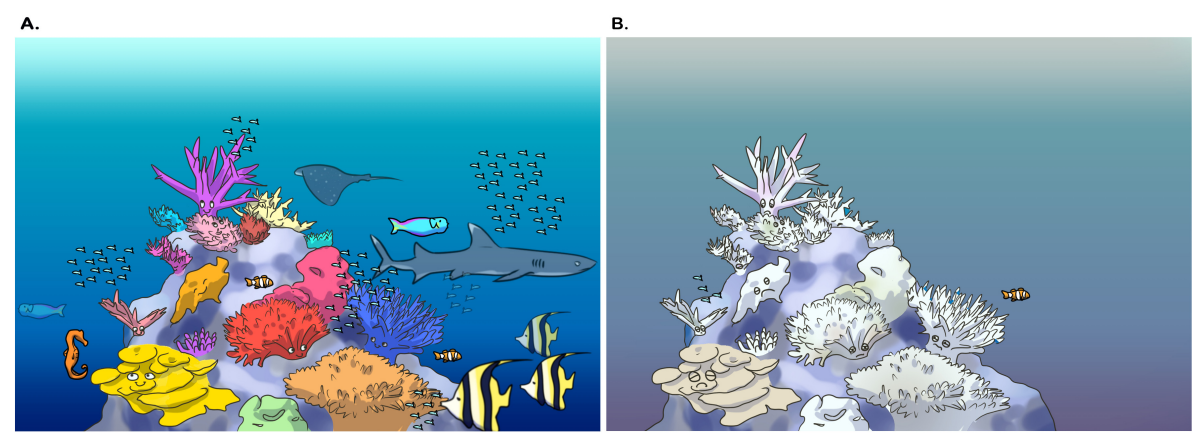

Figure 1

\section{THE GREAT SAVIOR: PROBIOTICS}

Probiotics are microorganisms that can be used to bring health benefits to the organism they live in or on, which is called the host. In humans, for example, probiotics have been used to help with the digestion of food and to protect people from invasion by illness-causing microorganisms known as pathogens. M\&Ms are good candidates for use as probiotics, because these organisms are already known to provide benefits for their hosts. Positive interactions between M\&Ms and their hosts do not occur only in humans and corals. Many plants also use a mutualistic relationship with microorganisms to grow. Legumes, which include important grain-producing plants like beans, peas, and peanuts, are a good example. Legumes have microorganisms living inside their roots, and some of them are called plant growth-promoting rhizobacteria. These beneficial microorganisms provide the legumes with nitrogen, which is an essential element for strong plant growth.

Could it be that providing more mutualistic microorganisms to struggling corals might help them to survive in higher water temperatures? Although corals do not have digestive tracts like humans, or roots like plants, they still have several microorganisms associated with them that can be beneficial. These microorganisms protect corals against pathogens, act as food for the corals, or provide some micronutrients that corals need to grow [4]. So maybe we can also use the good microorganisms that live with corals as probiotics. Researchers around the world have been studying whether probiotics can help corals when corals are endangered by rising ocean temperatures.

A recent study showed that, yes, probiotics may help corals survive during heat stress. In this study, the researchers isolated several microorganisms that live on corals and grew them in the lab. All these microorganisms were tested, using various laboratory techniques, to find out which microorganisms could potentially help weakened corals to survive. The researchers found seven such "potential super microorganisms" and did an experiment to see if 
Figure 2

Coral probiotics help corals to survive high water temperatures. (A) Corals that are not protected by probiotics lose their zooxanthellae and become bleached when the temperature goes up $4^{\circ} \mathrm{C}$ above the ideal temperature. (B)

Corals that are protected by probiotics do not lose their zooxanthellae and maintain their color, even when the temperature goes up $4^{\circ} \mathrm{C}$ above the ideal temperature. This tells us that certain probiotic microorganisms can help to protect corals against increases in water temperature.
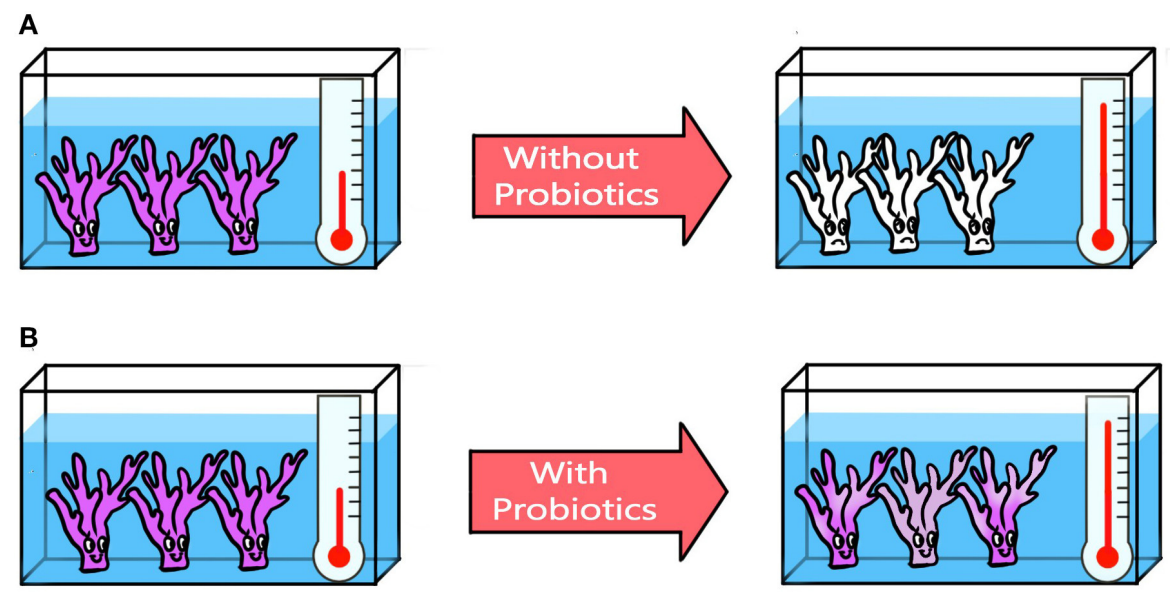

With

Probiotics

Figure 2

these microorganisms could actually act as probiotics and protect corals in rising water temperatures (Figures 2A,B). To visualize this experiment, imagine two aquariums the size of shoeboxes, each with water and three small corals (the size of ping pong balls) inside. The researchers then raised the water temperature of the two aquariums to a temperature at which the corals begin to weaken. In one aquarium, they added the potential probiotic microorganisms to the corals and in the other aquarium they just left the corals alone, without adding any probiotics. At the end of these experiments, the researchers saw that the corals that received the probiotics were much stronger, happier, and more colorful than the corals that did not receive probiotics. This was the first evidence that probiotics may help corals survive when they are sick or stressed by temperature increases. The "potential super microorganisms" tested could therefore be renamed "actual super microorganisms." An animation showing coral probiotics working is available at (https://youtu.be/toYkTciZyuQ). Remember that, so far, these probiotics have only been tested in the laboratory with a few coral species, so we do not yet know for sure if they would work on all corals in the actual ocean environment.

\section{HOW DO PROBIOTICS REALLY HELP CORALS?}

Researchers still do not understand exactly how probiotics help corals. It is possible that these probiotic microorganisms help to keep the mutualistic relationship between zooxanthellae and corals stable, reducing bleaching. Maybe microorganisms somehow manage to soothe this troubled relationship at higher temperatures, preventing corals from expelling the zooxanthellae, so the corals do not lose their main source of energy for growth.

A second possibility is that the probiotic microorganisms themselves could be supplying energy to corals, by releasing large amounts of nutrients or even being eaten directly by corals. If the probiotic 
microorganisms are somehow feeding the corals, the corals might feel less stress from losing some of the food that comes from the zooxanthellae. There are many possibilities as to how probiotic organisms help corals, and more studies are being done to discover and understand what really happens in this interaction among microorganisms, zooxanthellae, and corals.

\section{THE RED SEA: A POSSIBLE SOURCE OF PROBIOTICS}

Try to imagine a place where the average ocean temperature is naturally high. A place that has water temperatures warm enough that no coral from anywhere else in the world could survive. This place is the Red Sea, a region located between Africa and Asia. There, water temperatures can reach up to $33^{\circ} \mathrm{C}$ [5], while ocean temperatures elsewhere in the world where corals live are $\sim 25^{\circ} \mathrm{C}$.

This temperature difference between the Red Sea and other parts of the world may seem small, but for corals, which are so sensitive to temperature changes, this difference is very large and dangerous. Then how have corals lived happily for thousands of years in the Red Sea? Scientists think this could be because of the helpful microorganisms that these corals have. It is possible that these microorganisms have evolved with corals and have adapted to the high temperatures of the Red Sea, so they can give their corals enough strength to withstand these high temperatures. This makes the Red Sea a possible source of new probiotics to study.

Some studies are being conducted in the Red Sea to find new helpful microorganisms that can turn corals into super corals that are able to survive at high temperatures. If we find such microorganisms, we could use the microorganism to protect corals living in other regions of the world that suffer from high ocean temperatures. This may give these stressed corals a better chance to stay alive, and may also save the lives of all other sea creatures that make coral reefs their homes.

\section{ORIGINAL SOURCE ARTICLE}

Rosado, P. M., Leite, D. C. A., Duarte, G. A. S., Chaloub, R. M., Jospin, G., Nunes da Rocha, U., et al. 2018. Marine probiotics: increasing coral resistance to bleaching through microbiome manipulation. ISME J. 13:921-36. doi: 10.1038/s41396-018-0323-6

\section{REFERENCES}

1. Sheppard, C., Davy, S., Pilling, G., and Graham, N. 2018. The Biology of Coral Reefs. 2nd Edn. Oxford: Oxford University Press.

doi: 10.1093/oso/9780198787341.001.0001 
2. Hughes, T. P., Kerry, J. T., Alvarez-Noriega, M., Alvarez-Romero, J. G., Anderson, K. D., Baird, A. H., et al. 2017. Global warming and recurrent mass bleaching of corals. Nature 543:373-7. doi: 10.1038/nature21707

3. Gittins, J. R., D'Angelo, C., Oswald, F., Edwards, R. J., and Wiedenmann, J. 2015. Fluorescent protein-mediated colour polymorphism in reef corals: multicopy genes extend the adaptation/acclimatization potential to variable light environments. Mol. Ecol. 24:453-65. doi: 10.1111/mec.13041

4. Peixoto, R. S., Rosado, P. M., Leite, D. C. A., Rosado, A. S., and Bourne, D. G. 2017. Beneficial microorganisms for corals (BMC): proposed mechanisms for coral health and resilience. Front. Microbiol. 8:341. doi: 10.3389/fmicb.2017.00341

5. Sawall, Y., Al-Sofyani, A., Banguera-Hinestroza, E., and Voolstra, C. R. 2014. Spatio-temporal analyses of symbiodinium physiology of the coral Pocillopora verrucosa along large-scale nutrient and temperature gradients in the Red Sea. PLOS ONE 9:e103179. doi: 10.1371/journal.pone.0103179

SUBMITTED: 01 October 2019; ACCEPTED: 16 April 2020; PUBLISHED ONLINE: 22 May 2020.

EDITED BY: Rúben Martins Costa, King Abdullah University of Science and Technology, Saudi Arabia

CITATION: Rosado P, Varona N, Eisen JA and Peixoto RS (2020) An Incredible Invisible World: How Microorganisms Could Take Care of Corals in Difficult Times. Front. Young Minds 8:65. doi: 10.3389/frym.2020.00065

CONFLICT OF INTEREST: The authors declare that the research was conducted in the absence of any commercial or financial relationships that could be construed as a potential conflict of interest.

COPYRIGHT @ 2020 Rosado, Varona, Eisen and Peixoto. This is an open-access article distributed under the terms of the Creative Commons Attribution License (CC BY). The use, distribution or reproduction in other forums is permitted, provided the original author(s) and the copyright owner(s) are credited and that the original publication in this journal is cited, in accordance with accepted academic practice. No use, distribution or reproduction is permitted which does not comply with these terms.

\section{YOUNG REVIEWERS}

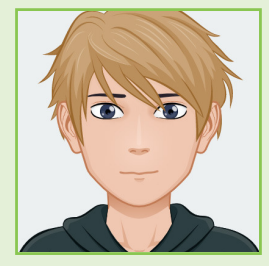

\section{BRAYDEN, AGE: 11}

I am from Montana in the USA and I like backpacking, snorkeling, floor hockey, science, learning about missions to Mars, and music. I have a dog named Geba and I like watching the Mandalorian.

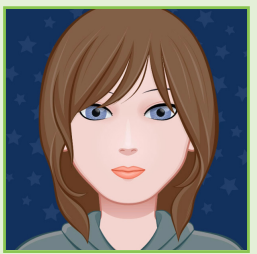

\section{CECILIA, AGE: 11}

$\mathrm{Hi}$, my name is Cecilia and I am 11 years old. I like reading and hiking. I also play the piano. 


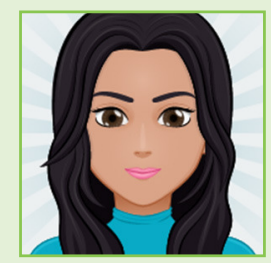

\section{NAGA, AGE: 15}

I am a 15 years old girl, only child, born and raised in India. I have been living in KAUST for 7 years. I love to sing and dance, and perform any kind of sports. I like theater, but not enough to perform live because I always forget my lines.

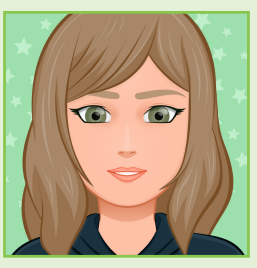

\section{SAGE, AGE: 10}

I am Sage, I like drawing, art, and playing my violin. I write stories and read my favorite books like Septimus Heap and Harry Potter. I am creative and like adventures, I like customizing clothes and making bracelets, and I am a good singer.

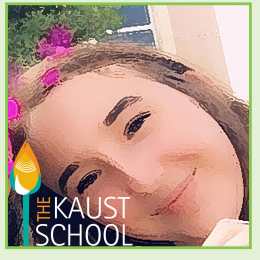

\section{SAVANA, AGE: 13}

I love dogs, my favorite color is red, and I love hanging out with my friends.

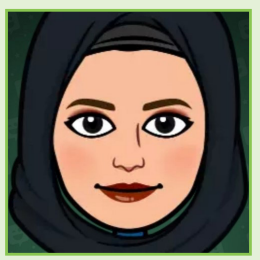

UMAIRAH, AGE: 15

My name is Umairah and I am 15 years old. I am from Malaysia but I have been living in Saudi Arabia for 7 years. I play volleyball and I enjoy Biology in school.

\section{AUTHORS}
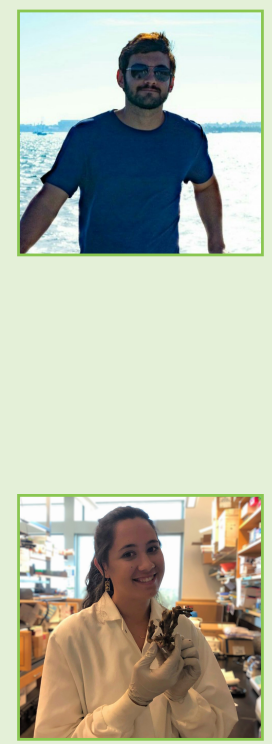

\section{PHILLIPE ROSADO}

I graduated in Biology from the State University of Rio de Janeiro (UERJ) (2015), completed a Master's degree at Federal University of Rio de Janeiro (UFRJ) (2017) on microbial ecology of marine environments and coral microbial manipulation. I am currently doing my Ph.D. at UFRJ, on manipulation of chemicals extracted from coral microbiota to increase coral resilience to thermal and oxidative stress. I have always been fascinated by aquariums and corals and how the invisible world of microbiota works in these environments. That is why I study corals, trying to protect this wonderful ecosystem from global warming.

\section{NATASCHA VARONA}

I was first exposed to coral research through an internship at the University of California Santa Cruz (UCSC) and immediately became hooked on these fascinating animals. After transferring from my community college to the University of California Davis (UCD) I wanted to do more to protect them, so I joined a lab at UCD that was doing research on probiotics for corals. I recently graduated with a degree in Biochemistry and Molecular Biology and I hope to get my Ph.D. related to coral research in the future. I also love art, like painting and drawing, and I decided to use that skill to communicate the importance of coral reefs and the threat they are facing. 


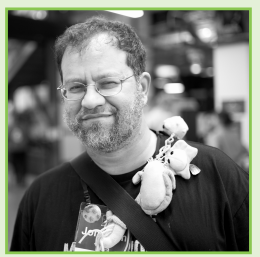

\section{JONATHAN A. EISEN}

I am a Professor at the University of California, Davis, a bit obsessed with all things microbial (and also with birds but that is for another time). I worked on microorganisms as an undergraduate at Harvard College (on beneficial symbionts of clams), as a Ph.D. student at Stanford University (on evolution and mutation in diverse microbes), and in my current and past faculty appointments (on communities of microorganisms, how they interact with each other and hosts, and methods for studying such communities). I am also an active and occasionally award-winning blogger and science communicator.

\section{RAQUEL S. PEIXOTO}

I am an Associate Professor at the Federal University of Rio de Janeiro (UFRJ) and currently Visiting Professor at the University of California, Davis. I have been working with beneficial microorganisms since my Master's studies (tracking bioindicators of pollution) and Ph.D. (at UFRJ, studying beneficial bacteria able to protect plants against disease). I merged my two passions (beneficial microorganisms and the ocean) by using the experience and inspiration obtained during my Ph.D. on the development and application of such concepts and ideas for marine organisms. I am very concerned about how global change and pollution are affecting marine ecosystems and so is Felipe, my 7 year old son. He says he wants to be a biologist to help saving corals, although he loves insects and says he wants to save bees, too.

*raquelpeixoto@micro.ufrj.br 